\title{
The Epileptic Encephalopathies of Infancy and Childhood
}

\author{
Elaine Wirrell, Kevin Farrell, Sharon Whiting
}

\begin{abstract}
The epileptic encephalopathies comprise a group of devastating seizure syndromes which begin in infancy and early childhood and usually result in intractable epilepsy. While some syndromes are relatively easily diagnosed early in their course, others take time to evolve, hampering an early, confident diagnosis. Epileptic encephalopathies are associated with slowing of cognitive function and evolution of severe behavioral disorders, which are often more distressing to families than the epilepsy. While an underlying etiology may explain some of this co-morbidity, many children have no identifiable etiology found for their seizures. In these "idiopathic" cases, recurrent subtle seizures, frequent epileptiform discharge and non-convulsive status epilepticus probably all play a role in deterioration of cognitive function and evolution of behavior disorders. This paper will review the most common epileptic encephalopathy syndromes, discuss the cognitive and behavioral co-morbidities and review current therapeutic options.
\end{abstract}

\begin{abstract}
RÉSUMÉ: Les encéphalopathies épileptiques du nourrisson et de l'enfant. Les encéphalopathies épileptiques incluent un groupe de syndromes épileptiques dévastateurs qui commencent dans la petite enfance et qui causent une épilepsie réfractaire au traitement. Bien que certains syndromes soient relativement faciles à diagnostiquer tôt au cours de la maladie, d'autres évoluent plus lentement ce qui retarde souvent le moment où un diagnostic ferme est posé. Les encéphalopathies épileptiques sont associées à un ralentissement des fonctions cognitives et au développement de troubles comportementaux sévères qui causent souvent plus de désarroi dans la famille que l'épilepsie. Bien qu'une pathologie sous-jacente peut expliquer en partie cette co-morbidité, on n'identifie chez plusieurs enfants aucune étiologie expliquant leurs crises. Chez ces cas «idiopathiques », des crises subtiles récurrentes, des décharges épileptiformes fréquentes et un état de mal épileptique non convulsif jouent probablement un rôle dans la détérioration de la fonction cognitive et l'évolution des troubles du comportement. Cet article revoit les syndromes encépahlopathiques épileptiques, discute les comorbidités cognitives et comportementales et revoit les options thérapeutiques actuelles.
\end{abstract}

Can. J. Neurol. Sci. 2005; 32: 409-418

The epileptic encephalopathies of childhood are amongst the most challenging seizure disorders to treat for the pediatric neurologist. The seizures associated with these syndromes are characteristically intractable to most conventional anti-epileptic drugs, although some do show response to specific therapies. Frequently, multiple seizure types are present, or evolve over time.

The cognitive and behavioral co-morbidity is even more catastrophic than the intractable seizures. The cardinal feature of the epileptic encephalopathies is that cognitive and behavioral deterioration occurs as a direct consequence of frequent seizures and epileptiform discharge and is not solely due to the underlying cause of the seizures. While a proportion of children with these syndromes are found to have an underlying etiology, including a malformation of cortical development, genetic or metabolic disorder, many have no identifiable, underlying etiology. Particularly for this "idiopathic" group, unless the epilepsy and marked electroencephalogram (EEG) abnormalities respond to therapy, the outcome is usually devastating.

Epileptic encephalopathies comprise a number of syndromes that tend to present at certain ages. ${ }^{1}$ Some of these can be readily diagnosed early in their course, whereas others take time to evolve, and a definitive diagnosis may not be made for months to years. This paper describes the most common epileptic encephalopathies of childhood, discusses the cognitive and behavioral co-morbidities and reviews the most effective treatments.

From the Departments of Pediatrics and Clinical Neurosciences, University of Calgary (EW), Calgary, AB, Canada; Department of Pediatrics, University of British Columbia (KF), Vancouver BC, Canada; Department of Pediatrics, University of Ottawa (SW), Ottawa, ON, Canada.

RECEIVED APRIL 28, 2005. ACCEPTED IN FINAL FORM JunE 26, 2005 Reprint requests to: Elaine Wirrell, Division of Pediatric Neurology, Alberta Children's Hospital, 1820 Richmond Rd SW, Calgary, AB Canada T2T 5C7 


\section{Epileptic Encephalopathy Syndromes (see Table)}

\section{Early Myoclonic Encephalopathy}

This syndrome presents in the neonatal period with erratic myoclonus which shifts from one part of the body to another. ${ }^{2}$ Myoclonus may become more prominent, and most infants also develop subtle partial seizures consisting of eye deviation and autonomic signs. When tonic spasms occur, they tend to do so later in the course. The EEG shows a suppression-burst pattern and the erratic myoclonus does not have an electrographic correlate. Some patients with this syndrome have an inborn metabolic error including non-ketotic hyperglycinemia, molybdenum cofactor deficiency, organic aciduria, aminoacidopathy and pyridoxine dependency, but structural brain abnormalities are very uncommon. No effective antiepileptic therapy exists and prognosis is very guarded. Approximately half of infants die by one to two years and survivors are usually left in a vegetative state.

\section{Early Infantile Epileptic Encephalopathy (Ohtahara syndrome)}

Infants present in the first few months of life with prominent tonic spasms that often occur in clusters, and partial motor seizures. ${ }^{3}$ Myoclonic seizures may occur but are not a prominent feature. The EEG shows a suppression-burst pattern in both wakefulness and sleep. Most infants have an underlying malformation of cortical development and inborn metabolic disorders are exceedingly rare. Mortality is high, and survivors usually evolve to West syndrome or refractory partial seizures. Although seizures are usually intractable, infants with cortical dysplasia may benefit from surgical treatment. ${ }^{4}$

\section{Migrating Partial Epilepsy in Infancy}

This rare condition presents in the first one to seven months of life with exceedingly frequent, multifocal, partial seizures often with autonomic or motor symptoms. ${ }^{5}$ The course may cycle between clusters of nearly continuous seizures interspersed with periods of relative quiescence. Ictal recording confirms the multifocal onset of seizures, and several focal seizures may be ongoing in the brain at any one time. However the seizures may be restricted to just one area for the first few months. ${ }^{6}$ Marked developmental regression occurs and infants are left with profound hypotonia. The underlying cause of this disorder is unknown. Brain imaging is normal and there have been no familial cases.

\section{West Syndrome}

West syndrome presents in infancy (peak age four to six months) and has been defined as a triad of infantile spasms, mental retardation and hypsarrhythmia. ${ }^{7}$ Mental retardation is usually not apparent at the onset and the occurrence of clusters of spasms associated with hypsarrhythmia on an interictal EEG has recently been recommended as the criteria for diagnosis of West syndrome. ${ }^{8}$ Spasms usually occur in clusters, often shortly after awakening. Asymmetric spasms are suggestive of possible focal cortical pathology. While approximately one third of infants are developmentally normal prior to the onset of West syndrome, most show a plateauing or regression of development with the emergence of spasms.
Hypsarrhythmia is the characteristic interictal EEG pattern but may occasionally be seen only during non-REM sleep. Furthermore, with age, hypsarrhythmia becomes less disorganized with greater interhemispheric synchronization. The term "modified hypsarrhythmia" has been used to describe less typical patterns. 9 The ictal recording is usually characterized by a high-amplitude slow wave often followed by diffuse fast rhythms or a period of electrodecrement.

Most cases of West syndrome are symptomatic of a preceding neurological insult (infection, hypoxia-ischemia), malformation of cortical development, neurocutaneous syndrome, chromosomal or single gene disorder or underlying inborn error of metabolism. Whereas cryptogenic cases may have a favorable long-term outcome, if treated early with appropriate therapy, symptomatic cases do less well.

\section{Severe Myoclonic Epilepsy in Infancy (Dravet's Syndrome)}

This syndrome begins in the first year of life with recurrent focal or secondarily generalized seizures that are often triggered by mild hyperthermia. ${ }^{10}$ Seizures are frequently prolonged leading to recurrent status epilepticus, switch sides from one event to the next and are extremely resistant to antiepileptic medications. Development is normal prior to the onset of seizures, but delay is evident by the second year of age. Between one and four years, the characteristic myoclonic seizures appear, frequently also with absences and partial seizures. Some patients, who present in infancy with the typical clinical features of severe myoclonic epilepsy do not develop myoclonic seizures but share the same course and outcome. The term Dravet's syndrome was developed to include such children. In the first year of life, investigations, including the EEG are often normal, hindering a confident diagnosis. However, generalized polyspike and spike-wave discharges and photosensitivity are often seen in the second or third years of life. Mutations in the Type 1 sodium channel (SCN1A) are frequently found in this condition, ${ }^{11}$ and more widespread availability of genetic testing may ultimately allow early definitive diagnosis.

\section{Lennox-Gastaut Syndrome}

Lennox-Gastaut syndrome most commonly begins in early childhood, with a peak age of two to eight years, and is defined by a triad of symptoms: (i) multiple types of generalized seizures, (ii) diffuse slow spike-wave on EEG and (iii) mental retardation. $^{12}$

Tonic seizures, considered by many to be the most characteristic seizure type, are usually very brief and are particularly prominent during sleep. These involve flexion of the neck and body, elevation of the arms and extension of the legs, and may be symmetric or asymmetric. However, in some cases, tonic seizures in sleep may be extremely subtle with minimal eye rolling or change in respiratory patterns. Atypical absences, atonic and myoclonic seizures are also characteristic and episodes of non-convulsive status epilepticus are frequent. Partial and generalized tonic-clonic seizures are less common.

Frontally predominant, $10-12 \mathrm{~Hz}$ activity is usually seen with tonic seizures and recording of this pattern on sleep EEG may assist earlier diagnosis. Attenuation of the EEG with or without low voltage fast activity is also a common ictal manifestation. 
Table: Epileptic Encephalopathy Syndromes

\begin{tabular}{|c|c|c|c|}
\hline Syndrome & Age at Onset & Seizure Types/Other Clinical & EEG Features \\
\hline $\begin{array}{l}\text { Early Myoclonic } \\
\text { Encephalopathy }\end{array}$ & Newborn & $\begin{array}{l}\text { Prominant myoclonus } \\
\text { Partial seizures, Tonic spasms }\end{array}$ & Suppression-burst \\
\hline $\begin{array}{l}\text { Early Infantile Epileptic } \\
\text { Encephalopathy }\end{array}$ & First few months & $\begin{array}{l}\text { Tonic spasms } \\
\text { Partial seizures }\end{array}$ & Suppression-burst \\
\hline $\begin{array}{l}\text { Migrating Partial } \\
\text { Epilepsy in Infancy }\end{array}$ & $1-7$ months & Multifocal partial seizures & Multifocal rhythmic theta \\
\hline West Syndrome & $\begin{array}{l}\text { Peak 4-6 months } \\
\text { Rare after } 12 \text { months }\end{array}$ & Infantile spasms & Hypsarrhythmia \\
\hline Dravet's syndrome & First year & $\begin{array}{c}\text { Often prolonged partial or } \\
\text { secondarily generalized seizures } \\
\text { with hyperthermia, myoclonus } \\
\text { after } 1 \text { year }\end{array}$ & $\begin{array}{l}\text { Often normal at onset. Generalized } \\
\text { polyspike and spike wave } \\
\text { activated with photic stimulation } \\
\text { after onset of myoclonus }\end{array}$ \\
\hline Lennox-Gastaut Syndrome & Early childhood, peak 2-8 years & $\begin{array}{c}\text { Atonic, atypical absence, tonic, } \\
\text { myoclonic }\end{array}$ & $\begin{array}{c}\text { Diffuse, frontally-predominant } \\
\text { slow spike wave usually }<2 \mathrm{~Hz}- \\
\text { often evolves over time. Frontal } \\
\mathbf{1 0 - 1 2 ~ H z ~ r h y t h m s ~}\end{array}$ \\
\hline Myoclonic-Astatic Epilepsy & Early childhood, 2-8 years & $\begin{array}{l}\text { Myoclonic-astatic, myoclonic, } \\
\text { astatic, atypical absence }\end{array}$ & $\begin{array}{l}\text { 2-3 Hz generalized spike-wave, } \\
\text { photoparoxysmal response } \\
\text { common. Parietal } 4-7 \text { Hz rhythms }\end{array}$ \\
\hline Atypical Benign Partial Epilepsy & Early childhood, 2-6 years & $\begin{array}{l}\text { Atypical absence, myoclonic, } \\
\text { atonic, partial or secondarily } \\
\text { generalized motor seizures }\end{array}$ & $\begin{array}{c}\text { Rolandic sharp waves, multifocal } \\
\text { sharp waves also commonly seen, } \\
\text { electrical status epilepticus in sleep } \\
\text { is common }\end{array}$ \\
\hline Landau-Kleffner Syndrome & Early childhood, 3-8 years & $\begin{array}{c}\text { Verbal auditory agnosia, } 75 \% \text { have } \\
\text { seizures which are usually partial } \\
\text { motor }\end{array}$ & $\begin{array}{l}\text { Awake recording usually shows } \\
\text { temporal spikes. In sleep, } \\
\text { discharges become increasingly } \\
\text { frequent and syndronous, and } \\
\text { may be continuous }\end{array}$ \\
\hline $\begin{array}{c}\text { Electrical Status Epilepticus in } \\
\text { Slow Sleep }\end{array}$ & Early childhood, 3-8 years & $\begin{array}{c}\text { Hyperkinesis, cognitive regression, } \\
\text { generalized minor seizures, partial } \\
\text { or secondarily generalized } \\
\text { motor seizures }\end{array}$ & $\begin{array}{l}\text { Electrical status epilepticus in } \\
\text { slow sleep }\end{array}$ \\
\hline
\end{tabular}

The most important features in making each diagnosis are indicated in bold.

The early interictal EEG pattern in Lennox-Gastaut syndrome is not well defined and the characteristic diffuse slow spike-wave discharge may take months to evolve. ${ }^{13}$ Early, confident diagnosis can be difficult in the absence of a history of tonic seizures and of the characteristic slow spike-wave pattern. ${ }^{14}$

Lennox-Gastaut syndrome can be subdivided into symptomatic and cryptogenic types, the latter of which have normal brain imaging, normal development prior to onset and no underlying identified etiology. Symptomatic cases, which account for nearly three quarters of children, are most often due to abnormalities of brain development but may also be due to brain injury in the perinatal period or in infancy. Approximately
$20 \%$ of patients have a prior history of West syndrome. ${ }^{15} \mathrm{~A}$ positive family history of epilepsy is present in 3-30\% of cases, with genetic factors playing a more significant role in cryptogenic cases. ${ }^{12,16}$

Long-term outcome is generally poor and most children show progressive intellectual deterioration with age. ${ }^{17}$ Poorer cognitive outcomes are predicted by onset prior to age three years and a prior history of West syndrome.

\section{Myoclonic Astatic Epilepsy}

This syndrome begins in the preschool years in children with normal neurological development and presents with frequent 
generalized tonic-clonic seizures, followed by minor motor seizures. ${ }^{18}$ The most characteristic type is the myoclonic astatic seizure but myoclonic, atonic, atypical absence and occasionally nocturnal tonic seizures may occur.

Several discriminating features have been suggested to help distinguish this syndrome from Lennox-Gastaut. Many have a positive family history of idiopathic generalized epilepsy whereas children with Lennox-Gastaut syndrome are more likely to have a past history of neurological problems and less commonly have a positive family history of epilepsy. Furthermore, tonic seizures are uncommon in myoclonic astatic epilepsy, and tend to occur later in the course of the disorder, whereas this is the prominent seizure type in Lennox-Gastaut syndrome. Finally, the interictal EEG pattern in myoclonic astatic epilepsy is characterized by $2-3 \mathrm{~Hz}$ generalized spikewave (compared to $1-2 \mathrm{~Hz}$ in Lennox-Gastaut), and both photosensitivity and 4-7 rhythms with parietal accentuation.

Genetic factors play a major role in myoclonic astatic epilepsy, which may be a manifestation of the syndrome, generalized epilepsy with febrile seizures "plus". ${ }^{19}$ The seizures remit after several years in $54-89 \%$ of patients ${ }^{20}$ and these children may have normal development or only mild cognitive difficulties. It is difficult to predict those who will remit but the development of tonic seizures suggests a poor prognosis for seizure control and mental development. Non-convulsive status is associated with a poor prognosis for mental development and may be induced by inappropriate treatment, such as carbamazepine, even in children who eventually achieve seizure remission. Avoidance of such medication and prompt treatment of status may reduce the acquired cognitive dysfunction in these children.

\section{Atypical Benign Partial Epilepsy (Pseudo-Lennox Syndrome)}

This syndrome begins between ages two to six years with multiple types of generalized minor seizures including atypical absences, atonic and myoclonic seizures. ${ }^{21} \mathrm{~A}$ high proportion of children also suffer simple partial seizures involving the orofacial region, which may secondarily generalize. However these focal seizures occur much less frequently than the minor seizures and tend to do so at night. The EEG shows rolandic sharp waves, which become increasingly synchronous in sleep, often evolving to bioelectric status epilepticus. Sharp waves are also frequently seen in parietal, temporal, occipital and frontal locations. Periods of intense seizure activity last usually several weeks and are interspersed by intervals of several months between the active periods before the seizures remit. Many patients have a good cognitive outcome but mental deterioration is often observed during periods of frequent seizures.

\section{Landau-Kleffner Syndrome and Electrical Status Epilepticus During Slow Sleep}

Landau-Kleffner syndrome most commonly presents with insidious onset of verbal auditory agnosia in a child aged three to eight years. ${ }^{22}$ Seizures occur in approximately three quarters of cases, and include generalized minor seizures as well as partial motor seizures with secondary generalization. The waking EEG usually shows high amplitude spike-waves, which are most often temporal spikes but can be parieto-occipital or even generalized. Electrical status epilepticus is seen in slow sleep in $85 \%$ of patients at some course in their illness. ${ }^{23}$ Hyperkinesis is common.

In electrical status epilepticus during slow sleep, both generalized and partial seizures are seen. With the onset of the EEG pattern, children show a marked deterioration in neuropsychological function with cognitive and behavioral decline as well as motor impairment. While the distinction between these two entities has been debated, some authors note that the location of neuropsychological dysfunction is more temporal in Landau-Kleffner syndrome, and more frontal in electrical status epilepticus during slow sleep. ${ }^{23}$

\section{Cognitive and Behavioral Co-morbidities in Epileptic Encephalopathies}

Cognitive function arrests or slows markedly in the epileptic encephalopathies. Mental regression may be gradual and not immediately apparent but most children are left with moderate to severe mental handicap. Studies on West syndrome suggest that $71-81 \%$ of children develop mental handicap ${ }^{24}$ although a single recent paper has suggested a more favorable outcome in cryptogenic patients treated early in their course with high-dose ACTH. ${ }^{25}$ Significant behavioral disorders are also common in the epileptic encephalopathies and adversely affect quality of life for these children and their families. Autism has been reported to develop in $13-33 \%$ of children with infantile spasms ${ }^{26,27}$ and in $70 \%$ of those with tuberous sclerosis. ${ }^{28}$ The risk of autism appears highest in children with temporal lobe tubers. ${ }^{29}$ In addition to autistic behaviors, Riikonen ${ }^{26}$ noted hyperkinesis in $23 \%$ of children with a prior history of infantile spasms. CassePerrot $^{30}$ found a high prevalence of hyperactivity, psychotic-type relationships and autistic traits in children with Dravet's syndrome. Of 27 children with Lennox-Gastaut seen in a single center over a 17 year period, all had behavior problems but the details of these problems were provided in only nine cases, seven $(26 \%)$ of whom had pervasive developmental disorder and two (7.4\%) of whom had psychosis. ${ }^{31}$ Other studies have noted a high prevalence of hyperkinetic behavior ${ }^{16}$ and apathy and slowed expression $^{32}$ in children with Lennox-Gastaut syndrome. Rare cases of remission of epilepsy and favorable outcome with Lennox-Gastaut syndrome are reported ${ }^{12}$ but in most patients, IQ falls over time. ${ }^{17,33}$

\section{Potential Causes of These Co-morbidities}

In some cases, an underlying etiology such as a diffuse malformation of cortical development or inborn error of metabolism can explain much of the profound cognitive delay. However, it is our impression that even these children can show meaningful cognitive improvement if seizure control and improvement in their EEG can be achieved. Various factors have been postulated to potentially impact on cognitive and behavioral co-morbidity including high doses of multiple antiepileptic drugs, frequent subtle seizures, frequent epileptiform discharge with transient cognitive impairment and non-convulsive status epilepticus.

\section{a. Antiepileptic Drugs}

The impact of antiepileptic drugs on cognition in children has been recently reviewed. ${ }^{34}$ Phenobarbital is the agent most 
strongly implicated in the literature to cause cognitive impairment. In studies of infants with febrile seizures, phenobarbital was associated with a higher risk of memory, concentration, fine motor and behavior problems. ${ }^{35-37}$ In one study comparing phenobarbital to placebo, mean IQ was 7.0 points lower in the phenobarbital group after two years of treatment. ${ }^{37}$ The effect of the other older antiepileptic drugs on cognition appears to be much smaller than phenobarbital, although mild memory and attentional difficulties ${ }^{38-40}$ and psychomotor slowing can be seen. ${ }^{41}$ There have been no comparative studies of the cognitive and behavioral side effects of the newer antiepileptic drugs in children, but cognitive side effects have been described in children receiving topiramate. An add-on, double-blind, randomized, placebo-controlled study in children with partial seizures found greater difficulties with attention and concentration (12\% vs $2 \%$ ) and memory (7\% vs $0 \%$ ) in the topiramate treated group. ${ }^{42}$ While long-term use of antiepileptic medications may contribute partly to cognitive impairment, it is unlikely to be the major factor causing this comorbidity in children with epileptic encephalopathies.

\section{b. Frequent "subtle" seizures and epileptiform discharge}

The dividing line between subtle seizures and epileptiform discharge with transient cognitive impairment is murky at best. Transient cognitive impairment has been defined as "an episode of cognitive impairment that occurs exclusively during epileptiform discharge without any other clinical signs". ${ }^{43}$ Interestingly, most studies of transient cognitive impairment have examined cognitive change associated with what have generally been considered to be interictal discharges. In studies of children undergoing cognitive testing during continuous EEG monitoring, left-sided discharges have been shown to affect verbal tasks and right-sided discharges affect non-verbal tasks. ${ }^{44}$ Aldenkamp ${ }^{43}$ studied the effect of brief seizures and frequent epileptiform discharge on cognitive function in 152 children aged 7-12 years. Importantly, this study excluded subjects with malignant syndromes such as epileptic encephalopathies. All children underwent EEG monitoring which was synchronized with computer cognitive testing. Short non-convulsive seizures were found to impair alertness, information processing and memory. The interictal EEG discharge had an additional effect, similar to brief seizures, but this effect was limited to those with very frequent discharges, defined as present in greater than $1 \%$ of the recording. The magnitude was smaller than for actual seizures, but the longer the discharge, the greater the impairment. While no similar study has been done in children with epileptic encephalopathy, the magnitude of impairment is probably even greater in these syndromes. Subtle "minor" seizures often occur at very high frequency and EEGs are often severely abnormal, with discharges present in much more than $1 \%$ of the recording.

\section{c. Non-Convulsive Status Epilepticus}

Non-convulsive status epilepticus is common in the epileptic encephalopathies, occurring in more than two-thirds of cases of Lennox Gastaut syndrome ${ }^{12}$ and $36 \%$ of cases of myoclonic astatic epilepsy. ${ }^{18}$ It is often diagnosed late and even when recognized, is often not aggressively treated. In the largest study of non-convulsive status epilepticus in children, Stores et $\mathrm{al}^{45}$ reported that only five of the 50 cases were recognized within few hours to days after onset, and only 20 of the 50 cases were suspected to be in non-convulsive status when the EEG was ordered. Only half of children were aggressively treated with intravenous benzodiazepines when the diagnosis was recognized. In a smaller study of 8 patients, the duration of nonconvulsive status epilepticus prior to diagnosis ranged from three days to four weeks. ${ }^{46}$ Recognition requires a high degree of suspicion to appreciate the change in mental awareness in a child who is usually already moderately impaired.

Although there have been few pediatric studies, there is clinical evidence to suggest that non-convulsive status epilepticus may lead to irrecoverable cognitive impairment in children with epileptic encephalopathies. Stores ${ }^{45}$ reported a convincing deterioration in mental functioning at last follow-up in seven of 18 children with Lennox Gastaut syndrome and seven of 13 with myoclonic astatic epilepsy following non-convulsive status epilepticus. However, it is not clear if this deterioration was a result of the episode of non-convulsive status or simply part of the natural history of having an epileptic encephalopathy. ${ }^{17,33}$ Similarly, four of the eight children reported by Manning ${ }^{46}$ regressed mentally following their episode of nonconvulsive status. While control of the status prevented further regression, patients did not recover to their previous intellectual level. Finally, in a survey of 101 patients with Lennox Gastaut syndrome in three epilepsy centers in Germany, a history of nonconvulsive status epilepticus was predictive of severe as compared to mild-moderate mental retardation with an odds ratio of $25 .{ }^{47}$ While this association might suggest that non-convulsive status epilepticus leads to cognitive deterioration, causality has not been proven. An alternative explanation is that both severe mental handicap and non-convulsive status epilepticus may simply be a reflection of a more relentless form of LennoxGastaut syndrome.

The above data suggest that prevention or effective treatment of non-convulsive status epilepticus may limit the mental handicap in these children. However, the literature also suggests that treatment of non-convulsive status epilepticus in children with epileptic encephalopathies is often unsuccessful. In the Stores ${ }^{45}$ study, intravenous benzodiazepines stopped the status in only 17 of the 25 children, and 8 of 17 relapsed once benzodiazepines were discontinued. Other studies have shown that only $15 \%$ of children with Lennox-Gastaut syndrome and non-convulsive status respond to benzodiazepines. ${ }^{48,49}$ Furthermore, benzodiazepines may, in some cases, exacerbate status epilepticus by triggering recurrent tonic seizures in children with Lennox-Gastaut syndrome. ${ }^{49-50}$ Other proposed treatment for non-convulsive status epilepticus in this population includes intravenous valproate, barbiturates, paraldehyde, steroids and inhalational anaesthesia. However, the paucity of literature in this area does not allow clear recommendations to be made regarding the "best" treatment.

In summary, the factors most likely to lead to the marked cognitive and behavioral co-morbidity in the epileptic encephalopathies are frequent subtle seizures and nonconvulsive status epilepticus. The long-term adverse effects of frequent "interictal" epileptiform discharges are unknown and the anti-epileptic drugs probably play only a minimal role in most cases. Clearly, more effective therapies are needed to favorably alter the cognitive outcomes in these children. 


\section{Current Therapies and Success Rates in the Epileptic Encephalopathies}

Anti-epileptic Drugs

One of the hallmarks of the epileptic encephalopathies is their poor response to conventional antiepileptic medications. Furthermore, there is evidence that some drugs may, in fact, exacerbate certain epilepsies. However, certain encephalopathies also appear to have a distinctive response to specific agents.

\section{Drugs which may exacerbate seizures}

Carbamazepine may aggravate absence, myoclonic and atonic seizures and provoke non-convulsive status epilepticus. ${ }^{51-}$ ${ }^{54}$ It may also worsen myoclonic seizures in the progressive myoclonic epilepsies and Angelman syndrome ${ }^{55}$ and may exacerbate Landau-Kleffner syndrome, electrical status epilepticus in slow sleep and atypical benign partial epilepsy. ${ }^{56}$ This drug should be avoided in cases with bilateral synchronous spike and wave discharges of $2.5-3 \mathrm{~Hz}$, and used with caution in children with mixed seizure disorders. ${ }^{53}$ Phenytoin may exacerbate absence and myoclonic seizures in symptomatic generalized epilepsy.54,57 Both carbamazepine and phenytoin may aggravate myoclonus in the progressive myoclonic epilepsies, and the more severe course and shortened lifeexpectancy in Finnish patients with Unverricht-Lundborg disease has been attributed to the use of phenytoin. ${ }^{57}$ Similarly, lamotrigine exacerbates both convulsive seizures and myoclonus in $80 \%$ of children with Dravet's syndrome. ${ }^{58}$ Finally, tiagabine may induce absence status ${ }^{59}$ and gabapentin has been reported to exacerbate absence seizures and myoclonus in Lennox-Gastaut syndrome. ${ }^{60}$

\section{Drugs with "Unique" Indications}

\section{a. Vigabatrin}

A recent Cochrane review meta-analysis confirmed the remarkable efficacy of vigabatrin in treating infantile spasms due to tuberous sclerosis complex. ${ }^{61}$ Spasms were controlled in $95 \%$ of children with tuberous sclerosis complex compared to only $54 \%$ of children with West syndrome due to other causes. Vigabatrin may also decrease the risk of autism in this population, although this finding needs to be confirmed in a larger study. ${ }^{62}$

\section{b. Stiripentol}

Stiripentol has been demonstrated in a double-blind, placebocontrolled study to have efficacy in Dravet's syndrome. When added to either clobazam or valproic acid, $71 \%$ of children receiving stiripentol versus only 5\% of the placebo group experienced a greater than $50 \%$ reduction in seizure frequency, and $43 \%$ of the stiripentol group achieved complete control of tonic-clonic seizures ${ }^{63}$ In an open study of add-on topiramate, $17 \%$ of patients became seizure-free and $56 \%$ had a reduction in seizure frequency by more than half. ${ }^{64}$

\section{c. Piracetam}

Piracetam has been shown to have remarkable efficacy in cortical myoclonus in two randomized, placebo-controlled studies. ${ }^{65-66}$ It was demonstrated to have efficacy in the progressive myoclonic epilepsies ${ }^{66-67}$ and also in a case series of Angelman syndrome ${ }^{68}$ Two case series have also suggested that zonisamide can be efficacious in the progressive myoclonic epilepsies, ${ }^{69-70}$ although this has not been proven in randomized, controlled studies.

\section{d. Sulthiame}

Sulthiame, a carbonic anhydrase inhibitor, has a unique ability to markedly reduce epileptiform discharge in children with benign focal epilepsy of childhood ${ }^{71}$ and may have a role in treatment of atypical benign focal epilepsy of childhood, Landau-Kleffner syndrome and electrical status epilepticus in slow sleep. However, while case reports have documented efficacy both in reduction of seizures and improved alertness and cognition, these claims need to be proven in more careful scientific studies.

Rarely, cases of intractable epilepsy may be related to deficiencies in certain vitamins. Intractable, infantile-onset epilepsies could be considered for a trial of pyridoxine, folinic acid and biotin, particularly if no underlying etiology can be found. ${ }^{72-74}$

Clearly, in certain of the epileptic encephalopathies, the use of very specific antiepileptic drugs may prove helpful. However, the majority of patients fail to benefit from antiepileptic drug therapy. While lamotrigine, topiramate and felbamate have been shown to be more effective than placebo in Lennox-Gastaut syndrome, their effects are modest at best. ${ }^{75-79} \mathrm{~A}$ recent Cochrane review summarized current therapeutic options for LennoxGastaut syndrome by stating "optimum treatment remains unknown .... no drug is highly efficacious". ${ }^{80}$

\section{Adrenocorticotrophic hormone (ACTH) and Steroid Use}

The major indication for ACTH or corticosteroids in pediatric epilepsy is in the treatment of West syndrome, although this therapy has also been used in Landau-Kleffner syndrome, electrical status epilepticus in slow sleep and, less commonly, in the other epileptic encephalopathies.

A recent review has summarized the evidence for the use of steroids and ACTH in children with infantile spasms. ${ }^{81}$ While there are discrepancies amongst the various studies ${ }^{82}$ ACTH appears superior to oral corticosteroids in the cessation of spasms and normalization of the EEG ${ }^{83-84}$ No clear conclusion can be drawn from the literature to support high versus low dose ACTH. Two studies compared high versus low dose ACTH and found no significant difference in response rate, normalization of the EEG or relapse rate. ${ }^{85-86}$ However, two other studies have documented very favorable long-term outcome in children with cryptogenic spasms who received high-dose ACTH early in their course. Despite no significant difference in acute spasm control between high-dose ACTH and oral corticosteroid, Lombroso ${ }^{87}$ found that patients with cryptogenic spasms treated with ACTH had a better developmental outcome and a lower frequency of other seizure types after long-term follow-up. More recently, Kivity reported that $100 \%$ of infants with cryptogenic spasms treated with high-dose ACTH within one month of onset were cognitively normal at long-term follow-up. ${ }^{25}$

Although steroids are considered standard treatment for Landau-Kleffner syndrome or electrical status epilepticus in 
slow sleep, the efficacy of this therapy has only been suggested in case series ${ }^{88-90}$ rather than documented in controlled trials. These two disorders are difficult to study due to large fluctuations in their clinical course, and often poor correlation between the severity of language impairment, EEG abnormalities and clinical seizures.

Case series have also suggested possible benefit of ACTH and corticosteroids in other refractory epileptic encephalopathies. Yamatogi ${ }^{91}$ found that over half of the 45 children with LennoxGastaut syndrome treated with ACTH became seizure-free, however most again relapsed over time. In a non-randomized study, Snead ${ }^{84}$ compared the use of ACTH to prednisone in 34 children with refractory generalized or partial seizures (excluding infantile spasms) Twelve of 18 (67\%) receiving ACTH versus $0 / 16$ treated with prednisone achieved seizure freedom, however $40 \%$ of the former group ultimately relapsed.

\section{Intravenous Gammaglobulin}

Intravenous gammaglobulin (IVIG) has been proposed as a potential therapy for refractory epilepsy in children. While response rates of up to $67 \%$ have been reported in case series, these favorable results have not been demonstrated in controlled studies. The only double-blind, placebo-controlled study in epilepsy used seven doses of 100-400 mg/kg of IVIG over a six week period. A $50 \%$ reduction in seizure frequency at six months was observed in $53 \%$ of those receiving IVIG versus $28 \%$ of those receiving placebo. These results did not achieve statistical significance, but the study involved only 61 adults and children and was underpowered..$^{92} \mathrm{~A}$ small add-on, placebo-controlled, crossover, single-blind trial of intravenous gammaglobulin in ten children with Lennox-Gastaut syndrome showed that only $20 \%$ of children experienced an immediate reduction in seizure frequency and EEG improvement. ${ }^{93}$ Further double-blind, placebo-controlled studies are needed to firstly determine efficacy, and then to define the optimal dosing regimen and timing of therapy.

\section{Ketogenic Diet}

The efficacy of the ketogenic diet in children with epileptic encephalopathies is difficult to determine because most efficacy studies have not analyzed the outcome in specific syndromes. Two recent prospective studies ${ }^{94-95}$ and a recent meta-analysis ${ }^{96}$ have shown that seizure-freedom is achieved in $10-15 \%$ of children with all types of refractory epilepsy, and 20-30\% experience a greater than $90 \%$ reduction in seizures. In studies focusing only on refractory infantile spasms, $14-35 \%$ of infants achieve complete seizure control with the ketogenic diet. ${ }^{97-98}$ The ketogenic diet was reported to be the most efficacious therapy in a retrospective case series of 81 children with myoclonic astatic epilepsy. ${ }^{99}$ It was also found to be effective in a small case series of Dravet's syndrome, in which nine of 15 children maintained the diet for a mean period of 24 months - seven of whom had a greater than $75 \%$ reduction in seizures. ${ }^{100}$ Similarly, in a small case series of 12 children with Lennox-Gastaut syndrome, one third had a greater than $90 \%$ reduction in seizures after six months on the diet. ${ }^{101}$ In the largest recent case series of 150 children starting the ketogenic diet at Johns Hopkins, 106 remained on the diet at six months. ${ }^{94}$ Thirty eight of these had either atonic, atypical absence or tonic seizures as their major seizure type. Two (5\%) were seizure-free and an additional 18 (47\%) had a greater than $90 \%$ reduction in seizures. There is no data on the effect of the ketogenic diet on cognition and behavior specifically in children with epileptic encephalopathies. However, in a prospective study of all cases of intractable epilepsy, there was a significant increase in mean developmental quotient at 12 months with significant behavioral improvements in attention and social functioning in cases treated successfully with the ketogenic diet. ${ }^{102}$

\section{Epilepsy Surgery}

Surgical resection of the epileptogenic region is a viable option in only a minority of children with epileptic encephalopathies. Cases of Ohtahara syndrome due to malformations of cortical development may benefit from epilepsy surgery. ${ }^{4}$ Surgical resection has also been reported to be effective in infants with West syndrome and intractable spasms due to cortical dysgenesis, both with regards to seizure control ${ }^{103}$ and in some cases, improvement in cognitive function. ${ }^{104}$ Fluorodeoxy-glucose (FDG) positron emission tomography (PET) may prove helpful in defining the epileptogenic zone in spasms due to cortical dysgenesis, and use of the tracer alpha methyltryptophan may discriminate epileptogenic from non-epileptogenic tubers in cases of tuberous sclerosis complex. ${ }^{105}$ With the exception of isolated case reports of focal cortical pathology with some of the other epileptic encephalopathies, ${ }^{106}$ resective surgery is generally not an option for other epileptic encephalopathies.

Multiple subpial transection has been reported in a limited number of small case series to be effective in some patients with refractory Landau-Kleffner syndrome. ${ }^{107-110}$ Further work is needed to determine the role of this operation in this syndrome.

Palliative surgical procedures have also been used in refractory encephalopathies, in an attempt to limit seizure severity and improve quality of life. Corpus callosotomy may benefit children with recurrent falls due to intractable tonic or atonic seizures. ${ }^{111-112}$ The role of vagal nerve stimulation is still uncertain in this population. Two prospective studies have failed to document marked benefit in most children with epileptic encephalopathies. Parker ${ }^{113}$ found only a $17 \%$ median seizure reduction at one year in 16 children with epileptic encephalopathy, although patients were perceived to have improved behavior. Similarly Aldenkamp ${ }^{114}$ noted only a $20.6 \%$ decrease in seizure frequency after two years in 19 children with Lennox-Gastaut syndrome and found no statistically significant improvements in cognitive function or quality of life. However, in a multicenter, retrospective review of 50 children with Lennox-Gastaut syndrome, Frost ${ }^{115}$ reported a median seizure reduction of $58 \%$ after six months. Two other small case series of children with Lennox-Gastaut syndrome reported marked improvement in seizure frequency in $23-83 \%$ of cases. ${ }^{116-117}$

\section{Future Directions}

At present, we recommend the following management strategy for children with epileptic encephalopathies:

a. Children with a resectable lesion causing seizures should be considered for early surgery

b. Specific anti-epileptic agents with unique efficacy for certain syndromes should be used early in the course 
c. Cases not falling into the above two categories should be considered early for the ketogenic diet

Unfortunately, the advances in epilepsy surgery and the wealth of new anti-epileptic drugs that have been introduced over the past 15 years have had minimal impact on most children with epileptic encephalopathies, who have persistent, intractable seizures despite our "best" therapies. Unless more effective treatments are found, children with these disorders will continue to have relentless cognitive and behavioral impairment in addition to refractory epilepsy.

A number of factors have hampered efforts to devise more effective therapies. The absence of an animal model of an epileptic encephalopathy has limited both investigation into the nature and etiology of the epileptic condition and associated cognitive impairment, and testing of new potential therapies. It is clear that most anti-epileptic medications showing efficacy in partial seizure models are not helpful in these conditions. In addition, most individual epileptic encephalopathies are relatively rare and no center sees large numbers of newly diagnosed patients, and so multicenter studies will be needed to assess therapies. Thus, operational definitions for the various syndromes will need to be agreed upon by pediatric epileptologists. These should have reasonably high diagnostic accuracy and still allow early identification of syndromes. Furthermore, the efficacy of specific treatments may well depend on when in the course of the encephalopathy they are given, as has been reported with ACTH in cryptogenic spasms. If an effective therapy is used after a long duration of frequent seizures and one or more bouts of prolonged non-convulsive status epilepticus, the cognitive outcome is likely to be poor. Finally, we need to consider other therapeutic strategies beside anti-epileptic drugs. Will neuroprotective agents reduce the cognitive and behavioral co-morbidity and ultimately also increase the likelihood of eventual seizure control? Is there any role for early, more aggressive therapies in these conditions? Should we consider high dose steroids or corticotrophin, intravenous gammaglobulin or the ketogenic diet at the time of diagnosis of certain epileptic encephalopathies? More timely identification and better treatment of non-convulsive status epilepticus should also be a priority. Further definition of specific gene disorders in some of these syndromes may allow for selection of specific therapeutic options and improve prognosis. There is clearly much more to learn about these conditions.

\section{ACKNOWLEDGMenTS}

The authors thank Drs Warren Blume, Lionel Carmant, Peter Camfield, Carter Snead and Gregory Holmes for their contributions to the Intractable Epilepsy conference where this topic was discussed.

\section{REFERENCES}

1. Commission on Classification and Terminology of the International League Against Epilepsy. Proposal for revised classification of epilepsies and epileptic syndromes. Epilepsia 1989;30:389-399.

2. Aicardi J. Early myoclonic encephalopathy. In: Roger J, Bureau M, Dravet C, Dreifuss FE, Perret A, Wolf P, (Eds). Epileptic Syndromes in Infancy, Childhood and Adolescence, 2 ed. London: John Libbey and Company, 1992:13-23.
3. Ohtahara S, Ohtsuka O, Yamatogi Y, Oka E, Inoue H. Early-infantile epileptic encephalopathy with suppression bursts. In: Roger J, Bureau M, Dravet C, Dreifuss FE, Perret A, Wolf P, (Eds). Epileptic Syndromes in Infancy, Childhood and Adolescence, 2 ed. London: John Libbey and Company, 1992:25-34.

4. Oka E, Ohno M, Minakuchi E, Ohtahara S. Indication of surgery for childhood epilepsy. Jpn J Psychiatry Neurol 1992;46:345-349.

5. Coppola G, Plouin P, Chiron C, Robain O, Dulac O. Migrating partial seizures in infancy: a malignant disorder with developmental arrest. Epilepsia 1995;36:1017-1024.

6. Dulac O. Epileptic encephalopathy. Epilepsia 2001;42 Suppl 3:2326.

7. Jeavons PM, Livet MO. West syndrome: infantile spasms. In: Roger J, Bureau M, Dravet C, Dreifuss FE, Perret A, Wolf P, (Eds). Epileptic Syndromes in Infancy, Childhood and Adolescence, 2 ed. London: John Libbey and Company, 1992:53-65.

8. Lux AL, Osborne JP. A proposal for case definitions and outcome measures in studies of infantile spasms and West syndrome: consensus statement of the West Delphi group. Epilepsia 2004;45:1416-1428.

9. Hrachovy RA, Frost JD, Jr., Kellaway P. Hypsarrhythmia: variations on the theme. Epilepsia 1984;25:317-325.

10. Dravet C, Bureau M Guerrini R, Giraud N, Roger J. Severe myoclonic epilepsy in infancy. In: Roger J, Bureau M, Dravet C, Dreifuss FE, Perret A, Wolf P, (Eds). Epileptic Syndromes in Infancy, Childhood and Adolescence, 2 ed. London: John Libbey and Company, 1992:75-88.

11. Kanai K, Hirose S, Oguni H, et al. Effect of localization of missense mutations in SCN1A on epilepsy phenotype severity. Neurology 2004;63:329-334.

12. Beaumanoir A DC. The Lennox-Gastaut syndrome. In: Roger J, Bureau M, Dravet C, Dreifuss FE, Perret A, Wolf P, (Eds). Epileptic Syndromes in Infancy, Childhood and Adolescence, 2 ed. London: John Libbey and Company, 1992:115-132.

13. Goldsmith IL, Zupanc ML, Buchhalter JR. Long-term seizure outcome in 74 patients with Lennox-Gastaut syndrome: effects of incorporating MRI head imaging in defining the cryptogenic subgroup. Epilepsia 2000;41:395-399.

14. Dulac O, N'Guyen T. The Lennox-Gastaut syndrome. Epilepsia 1993;34 Suppl 7:S7-17.

15. Markand ON. Lennox-Gastaut syndrome (childhood epileptic encephalopathy). J Clin Neurophysiol 2003;20:426-441.

16. Boniver C, Dravet C, Bureau M, Roger J. Idiopathic LennoxGastaut syndrome. Advances in Epileptology 1987;16:195-200.

17. Oguni H, Hayashi K, Osawa M. Long-term prognosis of LennoxGastaut syndrome. Epilepsia 1996;37 Suppl 3:44-47.

18. Doose H. Myoclonic astatic epilepsy of early childhood. In: Roger J, Bureau M, Dravet C, Dreifuss FE, Perret A, Wolf P, (Eds). Epileptic Syndromes of Infancy, Childhood and Adolescence, 2 ed. London: John Libbey and Company, 1992:103-114.

19. Scheffer IE, Wallace R, Mulley JC, Berkovic SF. Clinical and molecular genetics of myoclonic-astatic epilepsy and severe myoclonic epilepsy in infancy (Dravet syndrome). Brain Dev 2001;23:732-735.

20. Aicardi J. Myoclonic-astatic epilepsy. In: Wallace SJ, Farrell K, (Eds). Epilepsy in Children. London: Arnold, 2004;163-168.

21. Hahn A, Pistohl J, Neubauer BA, Stephani U. Atypical "benign" partial epilepsy or pseudo-Lennox syndrome. Part I: symptomatology and long-term prognosis. Neuropediatrics 2001;32:1-8.

22. Beaumanoir A. The Landau-Kleffner syndrome. In: Roger J, Bureau M, Dravet C, Dreifuss FE, Perret A, Wolf P, (Eds). Epileptic Syndromes in Infancy, Childhood and Adolescence, 2 ed. London: John Libbey and Company, 1992:231-243.

23. Tassinari CA, Bureau M, Dravet C, Dalla Bernardina B, Roger J. Epilepsy with continuous spikes and waves during slow sleep otherwise described as ESES (epilepsy with electrical status epilepticus during slow sleep). In: Roger J, Bureau M, Dravet C, Dreifuss FE, Perret A, Wolf P, (Eds). Epileptic Syndromes in Infancy, Childhood and Adolescence, 2 ed. London: John Libbey and Company, 1992:245-256. 
24. Jambaque I. Neuropsychological Aspects. In: Dulac O, Chugani HT, Dalla Bernardina B, (Eds). Infantile Spasms and West Syndrome, 1 ed. London: WB Saunders, 1994:82-87.

25. Kivity S, Lerman P, Ariel R, et al. Long-term cognitive outcomes of a cohort of children with cryptogenic infantile spasms treated with high-dose adrenocorticotropic hormone. Epilepsia 2004; $45: 255-262$

26. Riikonen R, Amnell G. Psychiatric disorders in children with earlier infantile spasms. Dev Med Child Neurol 1981;23:747-760.

27. Askalan R, Mackay M, Brian J, et al. Prospective preliminary analysis of the development of autism and epilepsy in children with infantile spasms. J Child Neurol 2003;18:165-170.

28. Hunt A, Dennis J. Psychiatric disorder among children with tuberous sclerosis. Dev Med Child Neurol 1987;29:190-198.

29. Bolton PF. Neuroepileptic correlates of autistic symptomatology in tuberous sclerosis. Ment Retard Dev Disabil Res Rev 2004;10:126-131.

30. Casse-Perrot C, Wolf M, Dravet C. Neuropsychological aspects of severe myoclonic epilepsy in infancy. In: Jambaque I, Lassonde M, Dulac O, (Eds). Neuropsychology of Childhood Epilepsy, 1 ed. New York: Kluwer Academic/Plenum Publishers, 2005:131140.

31. Boel MJ. Behavioural and neuropsychological problems in refractory paediatric epilepsies. Eur J Paediatr Neurol 2004;8:291-297.

32. Kieffer-Renaux V, Kaminska A, Dulac O. Cognitive deterioration in Lennox-Gastaut syndrome and Doose epilepsy. In: Jambaque I, Lassonde M, Dulac O, (Eds). Neuropsychology of Childhood Epilepsy, 1 ed. New York: Kluwer Academic/Plenum, 2001:185190.

33. Blume WT, David RB, Gomez MR. Generalized sharp and slow wave complexes: associated clinical features and long-term follow-up. Brain 1973;96:289-306.

34. Loring DW, Meador KJ. Cognitive side effects of antiepileptic drugs in children. Neurology 2004;62:872-877.

35. Camfield CS, Chaplin S, Doyle AB, et al. Side effects of phenobarbital in toddlers; behavioral and cognitive aspects. J Pediatr 1979;95:361-365.

36. Hellstrom B, Barlach-Christoffersen M. Influence of phenobarbital on the psychomotor development and behaviour in preschool children with convulsions. Neuropadiatrie 1980;11:151-160.

37. Farwell JR, Lee YJ, Hirtz DG, Sulzbacher SI, Ellenberg JH, Nelson KB. Phenobarbital for febrile seizures--effects on intelligence and on seizure recurrence. N Engl J Med 1990;322:364-369.

38. Stores G, Williams PL, Styles E, Zaiwalla Z. Psychological effects of sodium valproate and carbamazepine in epilepsy. Arch Dis Child 1992;67:1330-1337.

39. Forsythe I, Butler R, Berg I, McGuire R. Cognitive impairment in new cases of epilepsy randomly assigned to carbamazepine, phenytoin and sodium valproate. Dev Med Child Neurol 1991;33:524-534

40. Gallassi R, Morreale A, Di SR, et al. Cognitive effects of antiepileptic drug discontinuation. Epilepsia 1992;33 Suppl 6:S41-S44.

41. Aldenkamp AP, Alpherts WC, Blennow G, et al. Withdrawal of antiepileptic medication in children--effects on cognitive function: The Multicenter Holmfrid Study. Neurology 1993;43:41-50.

42. Elterman RD, Glauser TA, Wyllie E, et al. A double-blind, randomized trial of topiramate as adjunctive therapy for partialonset seizures in children. Topiramate YP Study Group. Neurology 1999;52:1338-1344.

43. Aldenkamp AP, Arends J. Effects of epileptiform EEG discharges on cognitive function: is the concept of "transient cognitive impairment" still valid? Epilepsy Behav 2004;5 Suppl 1:S25S34.

44. Kasteleijn-Nolst Trenite DG. Transient cognitive impairment during subclinical epileptiform electroencephalographic discharges. Semin Pediatr Neurol 1995;2:246-253.

45. Stores G, Zaiwalla Z, Styles E, Hoshika A. Non-convulsive status epilepticus. Arch Dis Child 1995;73:106-111.
46. Manning DJ, Rosenbloom L. Non-convulsive status epilepticus. Arch Dis Child 1987;62:37-40.

47. Hoffmann-Riem M, Diener W, Benninger C, et al. Nonconvulsive status epilepticus--a possible cause of mental retardation in patients with Lennox-Gastaut syndrome. Neuropediatrics 2000;31:169-174.

48. Tassinari CA, Daniele O, Michelucci R, et al. Benzodiazepines: efficacy in status epilepticus. Adv Neurol 1983;34:465-475.

49. Livingston JH, Brown JK. Non-convulsive status epilepticus resistant to benzodiazepines. Arch Dis Child 1987;62:41-44.

50. Tassinari CA, Dravet C, Roger J, Cano JP, Gastaut H. Tonic status epilepticus precipitated by intravenous benzodiazepine in five patients with Lennox-Gastaut syndrome. Epilepsia 1972;13:421435.

51. Shields WD, Saslow E. Myoclonic, atonic, and absence seizures following institution of carbamazepine therapy in children. Neurology 1983;33:1487-1489.

52. Lerman P. Seizures induced or aggravated by anticonvulsants. Epilepsia 1986;27:706-710.

53. Snead OC, III, Hosey LC. Exacerbation of seizures in children by carbamazepine. N Engl J Med 1985;313:916-921.

54. Osorio I, Reed RC, Peltzer JN. Refractory idiopathic absence status epilepticus: A probable paradoxical effect of phenytoin and carbamazepine. Epilepsia 2000;41:887-894.

55. Viani F, Romeo A, Viri M, et al. Seizure and EEG patterns in Angelman's syndrome. J Child Neurol 1995;10:467-471.

56. Corda D, Gelisse P, Genton P, Dravet C, Baldy-Moulinier M. Incidence of drug-induced aggravation in benign epilepsy with centrotemporal spikes. Epilepsia 200;42:754-759.

57. Eldridge R, Iivanainen M, Stern R, Koerber T, Wilder BJ. "Baltic" myoclonus epilepsy: hereditary disorder of childhood made worse by phenytoin. Lancet 1983;2:838-842.

58. Guerrini R, Dravet C, Genton P, et al. Lamotrigine and seizure aggravation in severe myoclonic epilepsy. Epilepsia 1998;39:508-512

59. Ettinger AB, Bernal OG, Andriola MR, et al. Two cases of nonconvulsive status epilepticus in association with tiagabine therapy. Epilepsia 1999;40:1159-1162.

60. Vossler DG. Exacerbation of seizures in Lennox-Gastaut syndrome by gabapentin. Neurology 1996;46:852-853.

61. Hancock E, Osborne JP. Vigabatrin in the treatment of infantile spasms in tuberous sclerosis: literature review. J Child Neurol 1999; 14:71-74.

62. Jambaque I, Chiron C, Dumas C, Mumford J, Dulac O. Mental and behavioural outcome of infantile epilepsy treated by vigabatrin in tuberous sclerosis patients. Epilepsy Res 2000;38:151-160.

63. Chiron C, Marchand MC, Tran A, et al. Stiripentol in severe myoclonic epilepsy in infancy: a randomised placebo-controlled syndrome-dedicated trial. STICLO study group. Lancet 2000;356:1638-1642.

64. Coppola G, Capovilla G, Montagnini A, et al. Topiramate as add-on drug in severe myoclonic epilepsy in infancy: an Italian multicenter open trial. Epilepsy Res 2002;49:45-48.

65. Brown P, Steiger MJ, Thompson PD, et al. Effectiveness of piracetam in cortical myoclonus. Mov Disord 1993;8:63-68.

66. Genton P, Guerrini R, Remy C. Piracetam in the treatment of cortical myoclonus. Pharmacopsychiatry 1999;32 Suppl 1:49-53.

67. Ikeda A, Shibasaki H, Tashiro K, Mizuno Y, Kimura J. Clinical trial of piracetam in patients with myoclonus: nationwide multiinstitution study in Japan. The Myoclonus/Piracetam Study Group. Mov Disord 1996 Nov;11(6):691-700.

68. Guerrini R, De Lorey TM, Bonanni P, et al. Cortical myoclonus in Angelman syndrome. Ann Neurol 1996 Jul;40(1):39-48.

69. Conry JA RSea. Efficacy of zonisamide in progressive myoclonic epilepsy: a case series. Ann Neurol 2001;50 (suppl 3):S104Abs.

70. Kyllerman M, Ben-Menachem E. Zonisamide for progressive myoclonus epilepsy: long-term observations in seven patients. Epilepsy Res 1998;29:109-114.

71. Rating D, Wolf C, Bast T. Sulthiame as monotherapy in children with benign childhood epilepsy with centrotemporal spikes: a 6month randomized, double-blind, placebo-controlled study. Sulthiame Study Group. Epilepsia 2000;41:1284-1288. 
72. Baxter P, Griffiths P, Kelly T, Gardner-Medwin D. Pyridoxinedependent seizures: demographic, clinical, MRI and psychometric features, and effect of dose on intelligence quotient. Dev Med Child Neurol 1996;38:998-1006.

73. Torres OA, Miller VS, Buist NM, Hyland K. Folinic acidresponsive neonatal seizures. J Child Neurol 1999;14:529-532.

74. Wolf B, Heard GS, Weissbecker KA, et al. Biotinidase deficiency: initial clinical features and rapid diagnosis. Ann Neurol 1985;18:614-617.

75. Eriksson AS, Nergardh A, Hoppu K. The efficacy of lamotrigine in children and adolescents with refractory generalized epilepsy: a randomized, double-blind, crossover study. Epilepsia 1998;39:495-501.

76. Sachdeo RC, Glauser TA, Ritter F, et al. A double-blind, randomized trial of topiramate in Lennox-Gastaut syndrome. Topiramate YL Study Group. Neurology 1999;52:1882-1887.

77. Coppola G, Caliendo G, Veggiotti P, et al. Topiramate as add-on drug in children, adolescents and young adults with LennoxGastaut syndrome: an Italian multicentric study. Epilepsy Res 2002;51:147-153.

78. Motte J, Trevathan E, Arvidsson JF, et al. Lamotrigine for generalized seizures associated with the Lennox-Gastaut syndrome. Lamictal Lennox-Gastaut Study Group. N Engl J Med 1997;337:1807-1812.

79. Efficacy of felbamate in childhood epileptic encephalopathy (Lennox-Gastaut syndrome). The Felbamate Study Group in Lennox-Gastaut Syndrome. N Engl J Med 1993;328:29-33.

80. Hancock E, Cross H. Treatment of Lennox-Gastaut syndrome. Cochrane Database Syst Rev 2003;(3):CD003277.

81. Mackay MT, Weiss SK, ms-Webber T, et al. Practice parameter: medical treatment of infantile spasms: report of the American Academy of Neurology and the Child Neurology Society. Neurology 2004 May 25;62(10):1668-1681.

82. Hrachovy RA, Frost JD, Jr., Kellaway P, Zion TE. Double-blind study of ACTH vs prednisone therapy in infantile spasms. J Pediatr 1983;103:641-645.

83. Baram TZ, Mitchell WG, Tournay A, et al. High-dose corticotropin (ACTH) versus prednisone for infantile spasms: a prospective, randomized, blinded study. Pediatrics 1996;97:375-379.

84. Snead OC, III, Benton JW, Myers GJ. ACTH and prednisone in childhood seizure disorders. Neurology 1983;33:966-970.

85. Hrachovy RA, Frost JD, Jr., Glaze DG. High-dose, long-duration versus low-dose, short-duration corticotropin therapy for infantile spasms. J Pediatr 1994;124(5 Pt 1):803-806.

86. Yanagaki S, Oguni H, Hayashi K, et al. A comparative study of high-dose and low-dose ACTH therapy for West syndrome. Brain Dev 1999;21:461-467.

87. Lombroso CT. A prospective study of infantile spasms: clinical and therapeutic correlations. Epilepsia 1983;24:135-158.

88. Marescaux C, Hirsch E, Finck S, et al. Landau-Kleffner syndrome: a pharmacologic study of five cases. Epilepsia 1990;31:768-777.

89. Lerman P, Lerman-Sagie T, Kivity S. Effect of early corticosteroid therapy for Landau-Kleffner syndrome. Dev Med Child Neurol 1991;33:257-260.

90. Tsuru T, Mori M, Mizuguchi M, Momoi MY. Effects of high-dose intravenous corticosteroid therapy in Landau-Kleffner syndrome. Pediatr Neurol 2000;22:145-147.

91. Yamatogi Y, Ohtsuka Y, Ishida T, et al. Treatment of the Lennox syndrome with ACTH: a clinical and electroencephalographic study. Brain Dev 1979;1:267-276.

92. van Rijckevorsel-Harmant K, Delire M, Schmitz-Moorman W, Wieser HG. Treatment of refractory epilepsy with intravenous immunoglobulins. Results of the first double-blind/dose finding clinical study. Int J Clin Lab Res 1994;24:162-166.

93. Illum $\mathrm{N}$, Taudorf $\mathrm{K}$, Heilmann $\mathrm{C}$, et al. Intravenous immunoglobulin: a single-blind trial in children with LennoxGastaut syndrome. Neuropediatrics 1990;21:87-90.

94. Freeman JM, Vining EP, Pillas DJ, et al. The efficacy of the ketogenic diet-1998: a prospective evaluation of intervention in 150 children. Pediatrics 1998;102:1358-1363.
95. Vining EP, Freeman JM, Ballaban-Gil K, et al. A multicenter study of the efficacy of the ketogenic diet. Arch Neurol 1998;55:14331437.

96. Lefevre F, Aronson N. Ketogenic diet for the treatment of refractory epilepsy in children: A systematic review of efficacy. Pediatrics 2000;105:E46.

97. Nordli DR, Jr., Kuroda MM, Carroll J, et al. Experience with the ketogenic diet in infants. Pediatrics 2001;108:129-133.

98. Kossoff EH, Pyzik PL, McGrogan JR, Vining EP, Freeman JM. Efficacy of the ketogenic diet for infantile spasms. Pediatrics 2002;109:780-783.

99. Oguni H, Tanaka T, Hayashi K, et al. Treatment and long-term prognosis of myoclonic-astatic epilepsy of early childhood. Neuropediatrics 2002;33:122-132.

100.Fejerman N, Caraballo R, Cersosimo R. Ketogenic diet in patients with Dravet syndrome and myoclonic epilepsies in infancy and early childhood. Adv Neurol 2005;95:299-305.

101.Moreno Villares JM, Oliveros-Leal L, Simon-Heras R, MateosBeato $\mathrm{F}$. [The return to the ketogenic diet. What role does it play in the treatment of refractory seizures of infancy?]. Rev Neurol 2001;32:1115-1119.

102.Pulsifer MB, Gordon JM, Brandt J, Vining EP, Freeman JM. Effects of ketogenic diet on development and behavior: preliminary report of a prospective study. Dev Med Child Neurol 2001;43:301-306.

103. Chugani HT, Shewmon DA, Shields WD, et al. Surgery for intractable infantile spasms: neuroimaging perspectives. Epilepsia 1993;34:764-771.

104. Asarnow RF, LoPresti C, Guthrie D, et al. Developmental outcomes in children receiving resection surgery for medically intractable infantile spasms. Dev Med Child Neurol 1997;39:430-440.

105. Chugani DC, Chugani HT, Muzik O, et al. Imaging epileptogenic tubers in children with tuberous sclerosis complex using alpha[11C]methyl-L-tryptophan positron emission tomography. Ann Neurol 1998:44:858-866.

106.Quarato PP, Gennaro GD, Manfredi M, Esposito V. Atypical Lennox-Gastaut syndrome successfully treated with removal of a parietal dysembryoplastic tumour. Seizure 2002;11:325-329.

107.Morrell F, Whisler WW, Smith MC, et al. Landau-Kleffner syndrome. Treatment with subpial intracortical transection. Brain 1995;118:1529-1546.

108. Buelow JM, Aydelott P, Pierz DM, Heck B. Multiple subpial transection for Landau-Kleffner syndrome. AORN J 1996;63:727-735, 737

109.Irwin K, Birch V, Lees J, et al. Multiple subpial transection in Landau-Kleffner syndrome. Dev Med Child Neurol 2001;43:248252.

110.Grote CL, Van SP, Hoeppner JA. Language outcome following multiple subpial transection for Landau-Kleffner syndrome. Brain 1999;122:561-566.

111. Cendes F, Ragazzo PC, da C, V, Martins LF. Corpus callosotomy in treatment of medically resistant epilepsy: preliminary results in a pediatric population. Epilepsia 1993;34:910-917.

112.McInerney J, Siegel AM, Nordgren RE, et al. Long-term seizure outcome following corpus callosotomy in children. Stereotact Funct Neurosurg 1999;73:79-83.

113.Parker AP, Polkey CE, Binnie CD, et al. Vagal nerve stimulation in epileptic encephalopathies. Pediatrics 1999;103:778-782.

114.Aldenkamp AP, Majoie HJM, Berfelo MW, et al. Long-term effects of 24-month treatment with vagus nerve stimulation on behaviour in children with Lennox-Gastaut syndrome. Epilepsy Behav 2002;3:475-479Abs.

115.Frost M, Gates J, Helmers SL, et al. Vagus nerve stimulation in children with refractory seizures associated with Lennox-Gastaut syndrome. Epilepsia 2001;42:1148-1152.

116.Hosain S, Nikalov B, Harden C, Li M, Faser R, Labar D. Vagus nerve stimulation treatment for Lennox-Gastaut syndrome. J Child Neurol 2000;15:509-512.

117.Hornig GW, Murphy JV, Schallert G, Tilton C. Left vagus nerve stimulation in children with refractory epilepsy: an update. South Med J 1997;90:484-488. 